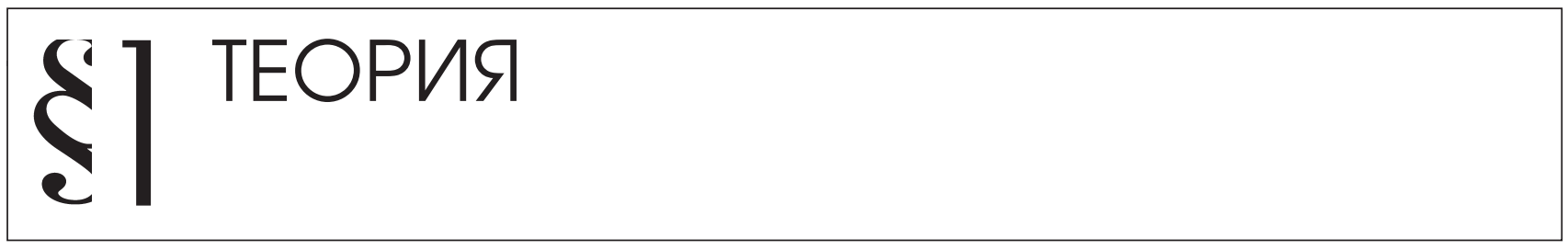

\title{
РЕСУРСЫ СИНЕРГЕТИЧЕСКОГО ПОДХОДА В СОВРЕМЕННОМ ТЕОРЕТИЧЕСКОМ ПРАВОВЕДЕНИИ: ОПЫТ ИССЛЕДОВАТЕЛЬСКИХ ПРАКТИК ОБЩЕПРАВОВОЙ ТЕОРИИ МАРГИНАЛЬНОСТИ
}

\begin{abstract}
Аннотация: Предметом исследования в настоящей статье являются особенности, закономерности и стохастические свойства и качества пограничных, неадаптированных и отчужденных от иенностей нормативного пространства правовых отношений. Автором статьи акиентируется внимание на вопросах причинности совершения правонарушений, обусловленной как объективными факторами (политическими, экономическими, культурными и др.), так и личностно-психологическими факторами, в своей совокупности детерминирующими негативное влияние правовой (юридической) маргинальности как самоорганизующейся, открытой и динамической системы на качество современного отечественного законопорядка. Методологией являются синергетический подход, а также методы правовой соичологии и юридического позитивизма, правовой психологии, антропологии права. Обосновываются выводы о целесообразности использования в теоретическом правоведении методологических принципов, способов и схем синергетики, представленных в опыте общеправовой теории маргинальности. На примере интерпретационной модели применения синергетического подхода обосновывается гипотеза о возможном использования данного подхода при изучении юридической наукой сложньх правовых системных образований.
\end{abstract}

Ключевые слова: Юридическая маргинальность, междисииплинарность, методология, синергетический подход, причинность правонарушений, бифуркации, диссипации, нелинейность, маргинальное поведение, предрасположенность.

Abstract: The subject of this research is the peculiarities, characteristics and stochastic qualities of the borderline legal relations, unadapted and foreign to the values of the normative sphere. The author pays particular attention on the issues of causality of committing legal violations motivated by both, the objective factors (political, economic, cultural, and others), as well as personal-psychological factors, which in their totality determine the negative effect of the legal (juridical) marginality as a self-organizing, open, and dynamic system upon the quality of modern Russian law and order. The article substantiates the conclusion on the reasonableness of the use of synergistic methodological principles and schemes within theoretical jurisprudence, presented within the experience of general legal theory of marginality. On the example of interpretational model of application of synergistic approach the author justifies the hypothesis on the possible implementation of this approach in study of complex legal systemic constructs by the juridical science.

Keywords: Bifurcation, causality of legal violations, synergystic approach, methodology, interdisciplinary methodology, legal marginality, dissipation, nonlinearity, marginal behavior, disposition.

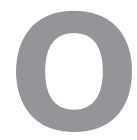

бщеправовая теория маргинальности как система полученных и производимых знаний, выдвигаемых гипотез и проблем об общих и специфических особенностях, закономерностях а также вероятностных (стохастических) факторах негативного влияния феномена пограничности, отчужденности и неадаптированности (маргинальности) на качество правовых отношений и состояние законопорядка в целом, отдельное внимание уделяет историческим и со- временным процессам формирования индивидуального и коллективного правосознания и правовой культуры маргинальной личности (групп) в механизмах детерминации анормативногоповедения.

Онтолого-гносеологические и аксиологические параметры исследуемой сферы имеют в российской и зарубежной науке свою хронологическую последовательность, рассмотренную и классифицируемую нами в работе «Генезис общеправовой теории маргинальности» 
(Казань, 2012 г.). Важность установления периодизации изучения данного сложнейшего социально-правового феномена в зарубежной и российской областях маргиналистики, обусловлена и способствует осмыслению эволюционных процедур исследовательских практик, начиная с изучения «маргинальности» как социологического понятия до его междисциплинарных значений. В настоящее время в современной российской науке защищено около 50-ти диссертационных работ в области философии, истории, социологии, политологии, психологии, правоведения (теория права и государства и криминология) и др., объектно-предметной сферой исследования которых является маргинальность в ее различных формах и проявлениях. Общенаучные фундаментальные исследования изучаемого феномена успешно осуществляются в зарубежной науке, а также международными организациями (JACS, NCCR) в Швейцарии (Цюрих) [1].

Методологические приемы, подходы и способы, используемые общеправовой теорией маргинальности, позволяют исследовать ее объектно-предметную сферу на двух уровнях:1) междисциплинарный, включающий в себя: а) философско-правовые, социолого-правовые, историко-правовые, социально-психологические, политико-правовые, экономико-правовые и др.; б) межотраслевые (теория и история права и государства, сравнительное правоведение, конституционное право, международное право, право социального обеспечения, криминология, уголовное право, административное право, гражданское право и т.д.); в) внутриотраслевые (история правовых учений, методология юридической науки, история права, история государства и т.д.); 2) институциональный (непосредственно в формате теории права и государства), где анализируется правовое положение социальных групп (институтов), находящихся в маргинальном положении (обстоятельствах, ситуации), а также индивидуальные особенности и свойства маргинального поведения, правовой культуры и правосознания маргинальной личности, правовое положение маргинальных индивидов (групп), обосновываются основные направления антимаргинальной правовой политики и проч., изучению которых уделяется отдельное внимание.

В широком общенаучном контексте, правовая (юридическая) маргинальность рассматривается нами как феномен, обусловливающий специфические, рецессивные по отношению к ценностям и смыслам права, свойства (качества) основных субъектов правоотношений (в широком смысле - государства и личности), находящихся в «пограничной», переходной ситуации (положении), проявляющиеся в различных формах правового отчуждения: удвоении правовой реальности на мир «своих» и «чужих»; дисгармонии (дисбалансе) публичного и частного конфликтов; «параллельном» сосуществовании внутри официальной и неофициальной (теневой) правовой жизни, следствием чего становятся, с одной стороны - неудовлетворительное низкое качество, эффективность и результативность законодательства, принятие «неправовых» законов, с другой - совершение правонарушений, в т.ч. преступлений и т.д. [2]

На макросоциальном уровне, в контексте социологии права юридическая маргинальность, изучается нами как самоорганизующаяся система, обладающая рядом таких свойств как открытость, нелинейность, динамизм и др., со свойственными таким системам элементами диссипативного, бифуркационного и иного характера (категории синергетики), на рассмотрении которых далее мы остановимся более подробно.

Важно отметить, что изучение правовой маргинальности в синергетическом подходе вызвано прежде всего необходимостью изучения специфических особенностей индивидуального и группового поведения маргинальных субъектов, вопросов познания их стремлений и мотиваций к определенным образу жизни и соответствующему поведению (или отсутствие таковых) - как качественных характеристик, свойств и отношений индивидов (социальных групп) к окружающей социально-правовой реальности, имеющих нелинейные, полифункциональные и гетерогенные закономерности и зависимости. Учитывая, что юридическая маргинальность в известной мере неотделима непосредственно от социальной реальности, и не смотря на то, что основным элементом или даже центром такой действительности предстает сам человек, способный продуцировать отчужденность от права, или наоборот - минимизировать ее, выяснение каузальной природы правовой маргинальности, обусловленной внешними, порой непрогнозируемыми, факторами, в т.ч. несовершенством и неопределенностью целей и смыслов отдельных правовых источников, является необходимым условием познания сложных социально-правовых систем такого рода. В отличие от традиционного в юридическом позитивизме линейно-механистического объяснения причин изучаемой системы, синергетическая парадигма причинности представляется нам наиболее аутентичной и самодостаточной методологической схемой организации знаний такого рода [3].

Для становления и развития общеправовой теории маргинальности, помимо познания объективной приро- 
DOI: $10.7256 / 1811-9018.2015 .5 .15218$

При цитировании этой статьи сноска на доі обязательна

\section{Право и политика 5 (185) • 2015}

ды правовой маргинальности как самоорганизующейся системы, несомненно важное значение имеет изучение проблем формирования социально-психологических механизмов детерминации маргинальных процессов непосредственно в структуре маргинальной личности, находящейся в отчужденном, пограничном состоянии (обстоятельствах, положении), вызванных в т.ч. ситуационным, темпоральным характером проистекания биопсихологических и социокультурных изменений. Под такими механизмами следует понимать комплекс (систему) взаимосвязанных и взаимообусловливающих друг друга свойств и элементов (политических, экономических, культурных, правовых и др.), социальных закономерностей и особенностей макро-и микросреды (окружения), специфических биопсихологических и духовно-нравственных процессов, проистекающих внутри и за пределами (внешние проявления) правосознания маргинальных субъектов и т. д., которые в совокупности и во взаимодействии обусловливают и предопределяют формирование негативных последствий маргинальности в юридической сфере.

Траектории выбора средств, способов и методов изучения биопсихо-социокультурных факторов, задействованных в формировании таких сложных систем (феноменов) как правовая маргинальность, сталкиваются с проблемой методологического характера современной юридической науки, ранее нивелирующей значительным образом антропологическую, a, следовательно, естественно-гуманитарную сферу правовых исследований. В свою очередь, это послужило причиной и реактуализации междисциплинарного и популяризации синергетического подходов в выстраиваемой теории, в том числе объективизирующих познание личностно-субъективистских особенностей субъектов права (законодателя, правоприменителя и исполнителя правовых предписаний) в контексте глубинной антропоморфности самого права, имеющих и в том и другом случае, как видится, неравновесный и сложноуправляемый характер своегоразвития.

Очевидно, что такой ракурс постановки вопроса способствует значительному расширению применяемой в работе методологической «инженерии», интенционально ориентируя научную деятельность и процедурность из традиционной и общепринятой (в частности, в юридической науке) гуманитарной области познаний ещё и в естественно-гуманитарную сферу научной рациональности.

Гуманитарный подход, объемлющий всю совокупность правовых исследований, и в первую очередьеё отраслевуючасть, сосредоточен на анализе современ- ного текущего законодательства, его эффективности и результативности в регулировании и управлении общественными, в т.ч. правовыми отношениями и многом др. Выявление особенностей, закономерностей эмерджентных свойств, взаимосвязей и взаимодействий конкретных нормативных правовых актов с правовыми идеями, эмоциями и способами их выражения в правосознании, правовой культуре и поведении всех субъектов правоотношений становятся все более актуальными в теоретическом правоведении. Общеправовая теория маргинальности не является исключением из этого правила и акцентирует свое внимание как на изучении и анализе действующего международного и отечественного законодательства, так и на понимании и оценке его предназначения и целесообразности в представлениях о праве отдельных индивидов (групп, социума), а также о возможностях и способностях маргинальных субъектов воспринимать и исполнять предписания нормативноправовой сферы. В этом смысле, как представляется, естественно-гуманитарный подход, включающий в себя исследования в области социальной медицины, социальной психологии и психиатрии, девиантологии, аддиктологии и др., интегрирует и дополняет, а также способствует обогащению как общеправовой теории маргинальности, так и правовой науки в целом.

Проблема маргинальности, прямо или опосредовано находящаяся в сфере законодательного регулирования, обратила на себя пристальное внимание, прежде всего субъектов правотворчества в области международного права. Еще в 90-х годах прошлого столетия в Резолюции Генеральной Ассамблеи ООН от 14.12.1990 г. № 45/12 маргинальность рассматривалась как негативное социально-опасное явление, характеризующееся наличием в современных государствах значительного числа «рискогенных» групп переселенцев, мигрантов, беженцев, несовершеннолетних, воспитывающихся в неблагополучных семьях, лиц, злоупотребляющих спиртными напитками и наркотическими средствами и др. с устойчивыми стереотипами нежелательного поведения. Данная Резолюция призывает обратить внимание на проблемы маргинальности государственные органы, институты правосудия и правоохранительные системы, средства массовой информации и ученых, разрабатывающих программы и политику предупреждения правонарушений в формате совместной деятельности Организации Объединенных Наций [4].

Российская законодательная сфера также содержит ряд норм регулирующих некоторые виды маргинального поведения, это: административное законодательство 
отдельных субъектов и локальные нормативно-правовые акты, предусматривающие ответственность за бродяжничество, попрошайничество (Москва, Казань, Чебоксары, Красноярск); уголовная ответственность за вовлечение несовершеннолетних в занятие антиобщественной деятельностью (Ст. 151 УК РФ) и т.д.

Применение синергетического подхода в общеправовой теории маргинальности основано на теории самоорганизации нелинейных динамических сред («теория хаоса») и задает направления нового междисциплинарного видения сложных объектов (Г. Хакен, Г. Николс, И. Пригожин, Л. Розенфельд, П. Гленсдорф, И.Стенгерс, А. Баблоянц, Н. Моисеев и др.), обосновывая необходимость интегрального изучения законов проистекания социальных и физических явлений посредством их общенаучного наблюдения[5].

Одни и те же проблемы синергетической парадигмы (нелинейности, флуктуации, бифуркации, диссипации, аттракторы и т.д.) в рамках данного консолидированного подхода объясняют кинетический, включающий в себя: 1) динамический (наличие имманентных возможностей самоорганизации), 2) статистический (многоуровневая структура порядка в системе) характер образования микро-и полифундаментальных систем, в т.ч. социально-правовых [6, 791-793]. Такие самоорганизующиеся системы (подсистемы), находясь в состоянии покоя или незначительного неравновесия, способны выступать условием наступления порядка. Но при других обстоятельствах, когда деструктивные потенциал и энергия «резонансных зон» и локальных очагов «возмущающегося поведения», т.е. все то, что находится в беспорядочном состоянии вредных социальных «отходов» накладываются на неслучайные предпосылки, то эти неконтролируемые и непрогнозируемые процессы могут стать судьбоносными и вести к разрушению самого порядка [7].

Синергетическая парадигма, базирующаяся, в том числе, на принципе множественности знаний, обоснованном и актуализированном в середине прошлого столетия в процессе деятельности московского методологического кружка, разрабатывающего идеи системно-мыследеятельностной методологии (А. Зиновьев, Г. Щедровицкий, Б. Грушин, М. Мамардашвили и др.) [8] аккумулирует в себе совокупность не только однородных, но и гетерогенных знаний о сложных объектах познания. В данном подходе непременным условием является изучение объектно-предметной сферы путем рефлектирования в различные области науки. Коль скоро правовая маргиналистика включает в себя, как отмечено, два подхода изучения искомого феномена: гуманитарный и естественно-гуманитарный [9], то их совместное действие (синергетика), как представляется, может способствовать достижению целиобщенаучного познания проблем юридической маргинальности в формате самоорганизации систем более высокого порядка - общества и государства.

В 90-х годах прошлого столетия в работах Ю.С. Решетова обосновывались доктринальные положения о перспективах «философии плюрализма и толерантности» через призму синергетического методологического подхода. Автором отмечалось: «Сейчас мы столкнулись с такими жизненными реалиями, объяснение которых не укладывается в привычные рамки ... Ответить на эти вопросы поможет синергетика. Она утверждает, что сложным системам нельзя предопределять, навязывать пути развития. Общество является сложнейшей, открытой, неравновесной системой, в которой действуют процессы самоорганизации. Самое большое, что можно сделать - это воздействовать на резонансные зоны, чтобы ускорить присущие этой системе процессы. Зная будущее желательное состояние системы и следуя естественному ходу ее развития, можно попытаться выйти на новую форму организации. Идти вопреки законам самоорганизации сложной системы нельзя» [10].

Важность этих положений учтена при построении общеправовой теории маргинальности, в которой правовая маргинальность, с одной стороны, признается «резонансной зоной», деструктивным элементом более широких самоорганизующихся систем- правовой системы, права и далее - общества, государства. С другой стороны, правовая маргинальность исследуется как самостоятельная система (Целое), состоящая из множества самоорганизующихся систем менее масштабного характера - маргинальное поведение, маргинальное правосознание, правовое положение маргинальной личности, антимаргинальная правовая политика (Части, выступающие в ином контексте сами как самостоятельное Целое).

Процедуры композиций разноуровневых знаний, в частности, о правовой маргинальности и ее институциональных образований (объектно-предметная сфера исследования) и их репрезентация, проектирование в мыслительном и интерпретируемом автором образе Системы (модели), способствуют наиболее полному как теоретическому, так и практическому пониманию её сущностного содержания с помощью эвристических посылов синергетики в ее общенаучном, в т.ч. юридическом осмыслении. Поэтому правовое моделирование и создание кумулятивного эйдоса (образа) юридической (правовой) маргинальности как самоорганизующейся 
DOI: $10.7256 / 1811-9018.2015 .5 .15218$

При цитировании этой статьи сноска на доі обязательна

\section{Право и политика 5 (185) • 2015}

системы нелинейного характера - есть один из способов и методов осуществления исследований, в т.ч. для решения специально-юридических задач, поставленных общеправовой теорией маргинальности.

Синергетическая детерминация данных и аналогичных негативных социально-правовых системных образований (например, правонарушаемость, преступность) акцентирует свое внимание на совокупности: «... неконтролируемых и непрогнозируемых неопределенностей, способных выступать в роли случайных факторов, которые своими воздействиями на события и обстоятельства делают, действительность неподвластной тотальной регламентации ... Синергетика, имея междисциплинарное значение позволяет выстраивать более аутентичные объяснительные модели ... Основным предметом для синергетики выступают процессы самоорганизации в сложных, открытых, неравновесных системах. Ее интересуют два типа трансформаций ... а) переходы от хаоса к порядку, т.е. процессы возникновения новых форм; б) переходы от порядка к хаосу, т.е. деструктивные процессы распада систем ... Выводы синергетики указывают на то, что мечты об обществе, полностью подконтрольном властям и осуществляющим в русле однозначных управленческих воздействий, - это иллюзия, утопия» [6; 789, 791].

Как бы то не было, для юридической науки и практики необходимо осмысление того, что в неконтролируемых законом «социальных нишах», «зазорах», в беспорядочном состоянии «вредных социальных отходов» будут всегда существовать «очаги» не только ситуационных и случайных проявлений маргинального поведения индивидов, но и преднамеренно совершаемые ими правонарушения, в т.ч. преступления. Правоприминение, к сожалению, сталкивается уже со следствием «отчужденности» от права, прогнозирование же негативных и общественно-опасных последствий феномена юридической маргинальности, прежде всего зависит от науки и эффективности методологии исследований, используемых ею при изучении таких сложных социально-правовых явлений.

«Моделируя» правовую маргинальность в качестве устойчивой с точки зрения истории права, и неустойчивой с позиций синергетики, системы взаимосвязей разнообразных факторов различной природы и обусловленности, детерминирующих «отчужденность» государства и личности от права, и наоборот, конечно необходимо, как отмечалось, учитывать не только кинетические (статика и динамика) закономерности и особенности, но и стохастический (случайный) харак- тер их взаимодействия на что в настоящее время, правоведение уделяет недостаточно, на наш взгляд, внимание.

Кроме того, при помощи синергетики объясняется, что если в равновесном или слаборавновесном состоянии флуктуаций система (правовая маргинальность) функционирует достаточно стабильно, то при увеличении неравновесия она достигает «порога устойчивости» (стабильности), критические значения которого определяются как точки бифуркации. Один из двух возможных вариантов развития / деэволюции систем, в дальнейшем зависит уже от выбора наиболее приемлемых правовых способов (регуляторов) способствующих, выходу из этой ситуации для осуществления желаемого «мягкого бифуркационного перехода» в то или иное состояние, необходимого для существенной перестройки в целях равновесного упорядочивания элементов этой системы. В рамках одной из гипотез синергетики, в т.ч. общеправовой теории маргинальности, поясняется, что именно бифуркации являются источником нововведений и преобразований (инноваций) в развитии внешних и внутренних свойств природных и социально-правовых феноменов, если не случается обратного - деструкций систем более высокого порядка.

Такие менее также масштабные самоорганизующиеся системы (подсистемы) как правовая маргинальность, находясь в состоянии «покоя» или незначительного неравновесия, способны выступать, как уже отмечалось, условием оптимального порядка (правопорядка). Но при других обстоятельствах, когда деструктивные потенциал и энергия: «...локальных очагов «возмущающегося поведения», т.е. все то, что находится в беспорядочном состоянии вредных социальных «отходов» накладываются на неслучайные предпосылки, то эти «неконтролируемые и непрогнозируемые процессы могут стать судьбоносными и вести к разрушению самого порядка» [6, 791-793], справедливо отмечено В.А. Бачининым.

В действительности, в свете синергетического подхода, правотворчество и правоприменение в сфере правового регулирования маргинального поведения должно продуманно,деликатно и правомерно вторгаться в сферу свободы индивидуального, экзистенциального, культурного самоопределения личности, где перманентно на трансцендентном уровне осуществляют свою нормативно-регулятивную религия, мораль, деятельность и нравственность. Субъектам правотворчества важно учитывать тенденции самоорганизации самой правовой реальности, чтобы эффективно воздействовать на общественные отношения, например, этнорелигиозного характера [11], что относится к 
правотворческой и правоприменительной деятельности и должно являться необходимым условием для формирования научных общих стратегий антимаргинальной правовой политики.

Основными категориями синергетики, важными для выстраиваемой нами теории являются следующие понятия-концепты: 1) открытость системы, 2) нелинейность их развития; 3) диссипации и диссипативные структуры, 4) бифуркации, 5) аттракторы, 6) динамика социальной организации и др., рассмотрению которых уделяется отдельное внимание при исследовании правовой (юридической) маргинальности.

Дискурсивность положений синергетического подхода в изучении правовой маргинальности как самоорганизующейся исторически устойчивой / неустойчивой системы, функционирование которой обеспечивается амбивалентностью проявлений: 1) субъективистскобиопсихологических и культурных специфических особенностей маргинальных индивидов (групп), a также 2) отдельных энтропийных свойств социальноэкономической, политической, культурной сфер, законодательной и правоприменительной деятельности, в т.ч. по преодолению (превенции) негативных процессов и проявлений юридической маргинализации, в нашем исследовании объясняют наличие и взаимосвязь в ней следующих синергетических элементов:

I. Открытость правовой маргинальности как самоорганизующейся системы означает ее полифакторное взаимодействие с государством и социумом (политика, экономика, культура, право, в т.ч. правотворчество, право реализация, осуществление правовой антимаргинальной политики и т.д.), биопсихологической (правовое состояние, правовое сознание, правосубъектность, деликтоспособность маргинальных индивидов и др.) и духовно-нравственной (мотивационно-волевая сфера, религиозные убеждения, моральные принципы и др.), сферами, которые интенсифицируют (в случае коммуникаций деструктивного характера) процессы отчужденности, пограничности и дезакомодации, находящие свое прямое либо опосредованное, чаще всего негативное выражение в социально-правовом пространстве.

Способности, а также возможности проявлений разнообразных юридически-рецессивных качеств маргинальных локальных образований (субъектов) формируются и синтезируются в целостность правовой маргинальности. С другой стороны, развиваясь, они же экстраполируются в более обширные открытые системы - общество и государство.

II. Нелинейность развития правовой маргинальности означает не только закономерности процессов ее образования и функционирования в правовой реальности по объективным и субъективным причинам, но и стохастичность, эмерджентность проявления ее отдельных форм и видов. В частности, маргинальное поведение может формироваться в зависимости от воздействия (влияния) таких нелинейно-механистических факторов ситуационного характера как безработица, отсутствие средств к существованию, отсутствие родительской опеки, аффективность состояний, связанных со злоупотреблением алкоголя, наркотических средств, вследствии воздействия факторов «конфликтогенности» и влияния «психологии толпы», возникновения агрессивной реакции на насильственные методы разрешения конфликтов у этих групп, участвующих в детерминации анормативного поведения, совершении правонарушений, в т.ч. преступлений.

III. Диссипация (рассеивание) правовой маргинальности, т.е. возможность и способность этой системы отторгать или исключать несвойственные ей перманентные или ситуационные состояния, либо напротив, превращать их в однородно-отчужденную маргинальную структуру, входящую в содержание изучаемой системы. Например, изменение местоположения в статусно-правовом пространстве лиц, признанных безработными, лишенными родительских прав, нелегальными мигрантами, беженцами и т.д. и наоборот, прекращение этих статусов (безработного, снятие судимости, отмена ограничений в дееспособности и т.д.), видоизменяют структурно-статусное содержание системы акторов правовой маргинальности.

В части отдельных преобразований законодательной или правоприменительной сфер деятельности как диссипативных причин факторов возникновения правовой маргинальности, это может быть принятие или отмена (декриминализация) ранее эффективных для сохранения правопорядка правовых норм и введение «маргинализированных» правоустановлений, одобряемых, например, маргинальной кооперацией. Главной проблемой этой области является отсутствие реальной оценки эффективности, результативности, обратной связи, объясняющих действенность тех или иных «инновационных» преобразований в законотворчестве и правоприменении. Например, реформирование в конце 90-хх годов организационной структуры Министерства внутренних дел и, в частности, ликвидация служб профилактики, медицинских вытрезвителей, лечебнотрудовых профилакториев и т.д. непосредственным образом способствовало увеличению энтропийного «балласта», подверженного правовой и социальной маргинализации. Хаотичность состояния превентив- 
DOI: $10.7256 / 1811-9018.2015 .5 .15218$

При цитировании этой статьи сноска на доі обязательна

\section{Право и политика 5 (185) • 2015}

ной организации деятельности правоохранительных органов способствовала увеличению числа правонарушений, совершаемых маргинальными субъектами и возрастанию числа лиц, претерпевающих вредные последствия от их поведения.

$I V$. Бифуркации (раздвоения) правовой маргинальности, т.е. нахождение (пребывание) в точках «нестабильности», «пограничности» всех элементов в нее входящих, обусловливающих их положение на грани «правомерного» и «противоправного». В этих ситуациях даже случайные факторы могут изменять интенциональность состояний отчужденности в ту или иную сторону.

При этом, как отмечает В.А. Бачинин, роль случайности может приобретать принципиально важное значение «Почти ничтожная на входе, она может оказаться гигантской «на выходе» $[6,793]$.В связи с чем, в критических и непредсказуемых состояниях маргинальные субъекты (индивиды и группы) при принятии конкретных решений самостоятельно делают преимущественно неосознанный выбор, влияющий на дальнейшее развитие неправомерной юридической событийности.

Зоны бифуркации (пограничности) всегда имеют место в пространстве маргинальной личности, указывая на такие возможные последствия ее бифуркационных состояний как сублимация (т.е. возможность изменения негативных поведенческих мотиваций на позитивные) либо наоборот -протестные реакции, обусловливающие совершение правонарушений, в т.ч. преступлений, что собственно и характеризует в целом маргинальность.

Роль познания бифуркаций в полной мере можно соотнести срассмотрениемдеятельности законодателей или правоприменителей. Случайный (заведомо или спонтанно) характер при принятии того или иного решения может оказаться двойственным или же решающим для дальнейшей оценки его эффективности в качестве «правового» или «неправового» закона, «правовой» или «неправовой» практики его применения и проч.

$V$. Аттракторы, т.е. совокупность предпосылок (условий), вовлекающихразнообразные факторы причинности правовой маргинальности в движение к единому конечному, как правило, негативному результату. Индивиды, попав на зону аттрактора (например, устоявшейся маргинальной субкультуры), даже не желающие изначально полностью адаптироваться к ней, в конечном итоге теряют свою индивидуальность и сопротивляемость к этим условиям, приобретая свойства реципиетной субкультуры. Процессы правовой маргинализации, детерминированные собственными нравами, обычаями и традициями сложившихся, в частности, в преступных сообществах, организациях религиозного фундаменталистского толка и др., завершаются чаще всего совершением противоправных деяний, подтверждая тем самым неизбежность влияния деструктивной силы аттракторов на состояние законопорядка в целом. В связи с чем, непосредственно маргинальное поведение признается большинством правоведов как предрасположенное к совершению правонарушений.

VI. Динамика социальной самоорганизации правовой маргинальности характеризует и объясняет общие закономерности и особенности механизмов ее альтернативных и инвариативных (имманентных) возможностей самоорганизации в социально-правовом, либо внутреннем пространстве маргинальных субъектов. Направление «элементов» и форм проявления юридической маргинальности в «правовое русло» в известной степени зависит от эффективности правового регулирования или правового воздействия, а также отвыполнения стратегий правовой антимаргинальной политики [12] - как реальной, целесообразной, упорядоченной, системной деятельности, призванной «сбалансировать» общественные отношения на основе верховенства права.

Как отмечает О.Ю. Рыбаков, правовое развитие России не представляется линейным и программируемым. Право, выраженное в форме закона лишь тогда эффективно, когда оно функционирует на основе стабильной и мудрой правовой и социальной политики, нравственной экономики, политическом единстве, выполнении и укреплении конституционных основ государственности, соблюдении и защите прав и свобод личности, в рамках солидарных, партнёрскодоверительных отношений между государством и человеком с учетом реалий, сложностей и динамики общественных преобразований [13].

Таким образом, синергетический подход принимающий участие в междисциплинарных исследованиях общеправовой теории маргинальности, позволяет резюмировать, что познание систем такого рода, к каким на наш взгляд относится правовая маргинальность, открывает перед юридической наукой: «...неустойчивый мир, в котором малые причины порождают большие следствия» $[6,791]$.

Правовая маргинальность как самоорганизующаяся система, находящаяся перманентно в точках бифуркации и обладающая рядом рассмотренных нами 
свойств, на самом деле весьма сложно поддается какойлибо реструктуризации, тем более только при помощи юридических механизмов, средств и возможностей. Это должна быть обширная, полифункциональная система мер социального, политического, экономического, правового, культурного и иного характера, принимающая во внимание и прогнозирующая чрезвычайно нелинейные, неочевидные и сложно контролируемые процессы правовой маргинализации, которые должны безусловно учитываться при построении современной российской правовой политики.

В заключении хотелось бы отметить, что синергетическая методология, позволяющая объединять множество теоретических разработок различных сфер знаний и обладающая значительным эвристическим потенциалом и ресурсами для систематизации правовых научных исследований в целостном познании объектов как на теоретическом так и прикладном уровнях, по нашему мнению, может принести значимые позитивные результаты для юридической науки и практикив дальнейших разработках теорий правовой политики, предупреждения правонарушений, правовой культуры и правосознания, правового поведения и др., учениях о праве - как о самоорганизующихся системах.

Как отмечает в концептуальном исследовании, систематизирующем знания, понимание, интерпретационные модели и схемы при обосновании применения синергетического подхода в правоведении К.В. Шундиков: «Синергетика как междисциплинарный теоретический подход позволяет рассмотреть многие классические проблемы правовой науки в новых методологических координатах, а также привлекает внимание к вопросам, которые ранее не являлись предметом пристального внимания правоведов. Как первое, так и второе представляется полезным ресурсом дальнейшего развития юридического знания» [14].

\section{Библиография:}

1. Степаненко Р.Ф. Генезис общеправовой теории маргинальности: монография / Под ред. О.Ю. Рыбакова - Казань: «Университет управления «ТИСБИ», 2012. - С. 12-60.

2. Степаненко Р.Ф. Причинность, понятие и виды правовой маргинальности // Государство и право. - 2014. - № 6. - С. 99-100.

3. Степаненко Р.Ф. Институциональное содержание общеправовой теории маргинальности: монография / Под ред. О.Ю. Рыбакова. - Казань: «Университет управления «ТИСБИ», 2015. - 172 с.

4. Резолюция Генеральной Ассамблеи ООН от 14.12.1990 № 45/112. «Руководящие принципы Организации Объединенных Наций для предупреждения преступности среди несовершеннолетних. (Руководящие принципы, принятые в Эр-Рияде)» http://base.garant.ru/12123837/

5. Степаненко Р.Ф. Теоретико-методологические проблемы общеправовой концепции маргинальности // Ученые записки Казанского государственного университета. - 2011. - Т. 153. - Кн. 4. - С. 30-38.

6. Бачинин В.А. Энциклопедия философии и социологии права. - СПб.: Юрид. Центр ПРЕСС, 2006.

7. Пригожин И., Стенгерс И. Порядок их хаоса: Новый диалог человека с природой / Пер. с англ.: общ. ред.. В.И. Аршинова, Ю.Л. Климогтовича и Ю.В. Сачкова. - М.: Прогресс, 1986. - С. 269.

8. Мацкевич В.В. СМД-методология // Всемирная энциклопедия: Философия / Гл. науч. ред. и сост. А.А. Грицанов. - М.: АСТ, МН.: Харвест, Современный литератор // Можейко М.А. Истина. - 2001. - С. 789-794.

9. Степаненко Р.Ф., Чулюкин Л.Д. Общая теория маргинальности: проблемы правового подхода // Вестник экономики, права и социологии. - Казань. - 2/2011. - С. 96-104.

10. Решетов Ю.С, Методологические проблемы отечественного права // Ученые записки Казанского государственного университета. - Казань, 1969. - Т. 132. - С. 7, 8.

11. Степаненко Р.Ф., Степаненко Г.Н. Метафизические начала общеправовой концепции маргинальности // Философские перспективы: Московско-Казанский сб. ІІ Садыковские чтения, 24-25 октября 2014 года. - Казань: Изд-во Казан. ун-та, 2014. - Вып. II. - С. 66-73.

12. Степаненко Р.Ф. Понятие, основные виды и направления правовой политики в сфере правового регулирования процессов маргинализации // Право и политика. - 2014. - № 4 (172). - C. 493-504. DOI: 10.7256/1811-9018.2014.4.11711

13. Рыбаков О.Ю. Стратегия права: В поисках гармонии личности и государства // Стратегии правового развития России : монография / колл. авт.; под ред. О. Ю. Рыбакова. - М.: ЮСТИЦИЯ, 2015. - С. 9-16.

14. Шундиков К.В. Синергетический подход в правоведении. Проблемы методологии и опыт теоретического применения: монография. - М.: Юрлитинформ, 2013. - С. 231

\section{References (transliterated):}

1. Stepanenko R.F. Genezis obshchepravovoi teorii marginal'nosti: monografiya / Pod red. O.Yu. Rybakova - Kazan’: «Universitet upravleniya «TISBI», 2012. - S. 12-60.

2. Stepanenko R.F. Prichinnost', ponyatie i vidy pravovoi marginal'nosti // Gosudarstvo i pravo. - 2014. - № 6. - S. 99-100. 
DOI: $10.7256 / 1811-9018.2015 .5 .15218$

При цитировании этой статьи сноска на dоі обязательна

\section{Право и политика $5(185) \cdot 2015$}

3. Stepanenko R.F. Institutsional'noe soderzhanie obshchepravovoi teorii marginal'nosti: monografiya / Pod red. O.Yu. Rybakova. - Kazan': «Universitet upravleniya «TISBI», 2015. - $172 \mathrm{~s}$.

4. Stepanenko R.F. Teoretiko-metodologicheskie problemy obshchepravovoi kontseptsii marginal'nosti // Uchenye zapiski Kazanskogo gosudarstvennogo universiteta. - 2011. - T. 153. - Kn. 4. - S. 30-38.

5. Bachinin V.A. Entsiklopediya filosofii i sotsiologii prava. - SPb.: Yurid. Tsentr PRESS, 2006.

6. Prigozhin I., Stengers I. Poryadok ikh khaosa: Novyi dialog cheloveka s prirodoi / Per. s angl.: obshch. red.. V.I. Arshinova, Yu.L. Klimogtovicha i Yu.V. Sachkova. - M.: Progress, 1986. - S. 269.

7. Matskevich V.V. SMD-metodologiya // Vsemirnaya entsiklopediya: Filosofiya / Gl. nauch. red. i sost. A.A. Gritsanov. - M.: AST, MN.: Kharvest, Sovremennyi literator // Mozheiko M.A. Istina. - 2001. - S. 789-794.

8. Stepanenko R.F., Chulyukin L.D. Obshchaya teoriya marginal'nosti: problemy pravovogo podkhoda // Vestnik ekonomiki, prava i sotsiologii. - Kazan'. - 2/2011. - S. 96-104.

9. Reshetov Yu.S, Metodologicheskie problemy otechestvennogo prava // Uchenye zapiski Kazanskogo gosudarstvennogo universiteta. - Kazan', 1969. - T. 132. - S. 7, 8.

10. Stepanenko R.F., Stepanenko G.N. Metafizicheskie nachala obshchepravovoi kontseptsii marginal'nosti // Filosofskie perspektivy: Moskovsko-Kazanskii sb. II Sadykovskie chteniya, 24-25 oktyabrya 2014 goda. - Kazan': Izd-vo Kazan. un-ta, 2014. - Vyp. II. - S. 66-73.

11. Stepanenko R.F. Ponyatie, osnovnye vidy i napravleniya pravovoi politiki v sfere pravovogo regulirovaniya protsessov marginalizatsii // Pravo i politika. - 2014. - № 4 (172). - S. 493-504. DOI: 10.7256/1811-9018.2014.4.11711

12. Rybakov O.Yu. Strategiya prava: V poiskakh garmonii lichnosti i gosudarstva // Strategii pravovogo razvitiya Rossii: monografiya / koll. avt.; pod red. O. Yu. Rybakova. - M.: YuSTITsIYa, 2015. - S. 9-16.

13. Shundikov K.V. Sinergeticheskii podkhod v pravovedenii. Problemy metodologii i opyt teoreticheskogo primeneniya: monografiya. - M.: Yurlitinform, 2013. - S. 231 